\title{
Recovery, Well-Being, and Performance-Related Outcomes: The Role of Workload and Vacation Experiences
}

\author{
Charlotte Fritz \\ Technical University of Braunschweig
}

\author{
Sabine Sonnentag \\ University of Konstanz
}

\begin{abstract}
On the basis of theoretical assumptions regarding resource gain and loss (S. E. Hobfoll, 1998), the authors used a longitudinal study to examine effects of vacation on well-being and performance-related outcomes. University employees $(N=221)$ completed measures of well-being (health complaints and burnout) and performance-related outcomes (self-reported task performance and effort expenditure) 1 week before and 2 days and 2 weeks after vacation and measures of workload 2 days after vacation. Specific vacation experiences (positive and negative work reflection, relaxation, mastery experience, and nonwork hassles) were assessed during vacation. Results showed changes in well-being and self-reported effort expenditure from before to after vacation, revealing vacation effects and partial fade-out effects. In addition, vacation experiences and workload significantly predicted some of the outcomes. The authors discuss applicability of the theoretical approach in the context of vacation and fade-out effects, implications for future research on recovery processes, and practical implications.
\end{abstract}

Keywords: recovery, well-being, performance, burnout, vacation

Vacation, as a time off from work, offers the chance to recover from work demands and to build new resources. Although positive effects of vacation on employee well-being have been found, studies on the effects of vacation on performance-related outcomes are still rare and inconclusive (for a review, see Eden, 2001). In addition, the question remains whether there are specific vacation experiences that have an impact on recovery processes and subsequent well-being and performance-related outcomes.

Findings regarding specific vacation effects can provide information on how to create vacation experiences that result in improved well-being and higher job performance and on how to allocate work in organizations during and after an employee's vacation. Thus, our main goals with this study were to examine general effects of vacation as well as effects of specific experiences during or after vacation on well-being and performancerelated variables. In particular, we differentiated between experiences that consume resources and experiences that provide resources (Hobfoll, 1998). We applied a longitudinal design and assessed well-being and performance-related outcomes once before and two times after vacation.

Charlotte Fritz, Department of Psychology, Technical University of Braunschweig, Braunschweig, Germany; Sabine Sonnentag, Department of Psychology, University of Konstanz, Konstanz, Germany.

This study was part of Charlotte Fritz's' dissertation. We thank Jens Quandte and Nadine Lichtsinn for their help with data collection and Sandra Ohly and Paul Spector for helpful comments on drafts of this article.

Correspondence concerning this article should be addressed to Charlotte Fritz, who is now at the Department of Psychology, Bowling Green State University, Bowling Green, OH 43403. E-mail: fritzc@bgnet.bgsu.edu

\section{General Effects of Vacation on Well-Being and Performance-Related Outcomes}

Because during vacation, work demands normally are removed from the individual, this time allows for regeneration (Meijman \& Mulder, 1998), which may have an impact on well-being and performance-related variables when the individual is back at the workplace. Time off from work can be used to replenish resources (Eden, 2001). Resources can be described as valued objects, personal characteristics, or conditions (e.g., time, competencies, or skills; Hobfoll, 1998). Because resource loss increases experiences of stress, individuals strive to protect and build resources to increase their overall level of resources (Hobfoll, 1998). Recovery during vacation helps people to gain new resources, which may become apparent in increased well-being and higher job performance after vacation. Research using self-report as well as physiological measures has suggested that impaired well-being resulting from high levels of (persisting) stress at work can be restored through vacation (Eden, 1990; Glaser, Kiecolt-Glaser, Speicher, \& Holliday, 1985; Westman \& Eden, 1997).

In our study, we focus on burnout and health complaints as indicators of poor well-being. Burnout can be described as a strain reaction resulting from the accumulation of chronic daily stressors at work (Etzion, 1984). Demerouti, Bakker, Nachreiner, and Schaufeli (2001) differentiated between two subdimensions of burnout-namely, exhaustion, which is a result of prolonged physical, affective, and cognitive strain at work, and disengagement, which refers to distancing oneself from one's work and experiencing negative attitudes toward work. Demerouti et al. further assumed that burnout develops under high job demands and low job resources and may lead to loss of energy and motivation. Studies examining the effects of vacation on burnout have found that burnout levels decreased from before to immediately after vacation (Westman \& Eden, 1997; Westman \& Etzion, 2001), which indicates that the chance to build resources during vacation may lead 
to higher levels of resources and may become evident in lower levels of burnout after vacation.

Health complaints are a more general indicator of poor wellbeing and refer to various physical symptoms or minor problems (Watson \& Pennebaker, 1989), including headaches and disturbance of sleep. During vacation, frustration and pressure resulting from work demands can be reduced, and new resources can be gained. As a consequence, symptoms such as sleep problems or headaches may decrease. Thus, recovery processes during vacation may enhance people's general well-being by decreasing their level of health complaints.

There is still only little indication for effects of vacation on performance-related outcomes (Westman \& Aharon-Madar, 1998; Westman \& Etzion, 2001). We assume that recovering from work demands and building new resources during vacation have an impact on task performance when the employee returns to work. Task performance refers to behaviors that are part of the prescribed job requirements and that are regarded by formal reward systems (Williams \& Anderson, 1991). Having built up resources during a vacation may allow the employee to work more efficiently, thereby increasing daily task performance. In addition, availability of resources may lead to a decrease in effort that the employee needs to expend to fulfill the daily work tasks. Regulation of effort expenditure aims at ensuring task accomplishment at the required performance level (Hockey, 1997). Accordingly, we assume that the level of effort expenditure to reach a specific level of task performance may be influenced by the level of recovery (Meijman \& Mulder, 1998)

\section{Vacation Fade-Out}

Vacation research suggests that the positive effects of vacation subside within a short while after the employee's return to work. This means that well-being and performance-related outcomes return to their prevacation level 3 or 4 weeks after vacation (Eden, 1990; Westman \& Aharon-Madar, 1998; Westman \& Eden, 1997). Further examination of this fade-out effect can help us to understand its development over time (Westman \& Eden, 1997) and can reveal variables that support or slow down the underlying process. Therefore, we examined whether fade-out occurs as early as 2 weeks after the employee's return to work by assessing well-being and performance-related outcomes immediately after vacation and 2 weeks later.

On the basis of the assumption regarding resource gain (Hobfoll, 1998) and in accordance with earlier findings (Eden, 1990; Westman \& Eden, 1997), we assumed that health complaints and burnout would decrease from before to immediately after vacation. In addition, recovery during vacation may become evident in higher levels of reported task performance and lower levels of reported effort expenditure when the employee is back at the workplace. Furthermore, we expected that well-being and performance-related outcomes would return to their prevacation level 2 weeks after vacation because of the fade-out of vacation effects.

Hypothesis 1: Vacation will lead to an increase in well-being (reduced health complaints and reduced burnout) immediately after vacation.
Hypothesis 2: Vacation will lead to an increase in performance-related outcomes (self-reported task performance and reduced effort expenditure) immediately after vacation.

Hypothesis 3: Well-being (health complaints and burnout) will return to its prevacation level 2 weeks after vacation.

Hypothesis 4: Performance-related outcomes (self-reported task performance and effort expenditure) will return to their prevacation levels 2 weeks after vacation.

\section{The Role of Resource-Consuming and Resource- Providing Experiences During Vacation}

Researchers have speculated that there may be specific vacation experiences that foster or inhibit recovery processes, which, in turn, affect well-being and performance-related outcomes after vacation (Eden, 1990; Etzion, Eden, \& Lapidot, 1998; Lounsbury \& Hoopes, 1986). Vacation experiences that consume resources may pose additional demands on the individual, which become apparent in increased perceived stress, decreased well-being, and lower job performance after vacation. In contrast, vacation experiences that provide individual resources result in higher wellbeing and job performance after vacation.

\section{Resource-Consuming Vacation Experiences}

The consumption of resources may lead to stress, which, in turn, may have a negative impact on individual well-being and performance (Hobfoll, 1998). In addition, activities that consume resources may pose demands on the individual that hinder his or her recovery from work (Meijman \& Mulder, 1998). Accordingly, vacation experiences that consume resources decrease the overall level of resources and reduce well-being. Moreover, because of the consumption of resources, fewer resources will be available to be invested into work. As a consequence, task performance will be impaired. Furthermore, because of insufficient recovery during vacation, the employee may need more effort to fulfill his or her daily work tasks when back at the workplace. The resourceconsuming experiences we investigated are negative work reflection and nonwork hassles. Negative work reflection means thinking about the negative aspects of one's job and considering what one does not like about it. This experience may pose work-related demands on the individual that absorb additional resources and hinder recovery processes. Thus, negative thinking about jobrelated issues during off-work time could have detrimental consequences for well-being and performance-related outcomes (Etzion et al., 1998; Sonnentag \& Bayer, 2004). Another resourceconsuming experience during vacation that may impact recovery (Eden, 1990; Westman \& Eden, 1997) is nonwork hassles, such as conflicts with one's spouse or children or a breakdown of the car on a family trip. Nonwork hassles pose additional demands on the individual and consume resources, resulting in lower well-being as well as job performance.

Therefore, we hypothesized that negatively reflecting about the job and facing nonwork hassles during vacation would lead to an increase in health complaints, burnout, and reported effort expenditure and to a decrease in reported task performance after vacation. 
Hypothesis 5: Resource-consuming vacation experiences (negative work reflection and nonwork hassles) will lead to an increase in health complaints and burnout after vacation.

Hypothesis 6: Resource-consuming vacation experiences (negative work reflection and nonwork hassles) will lead to a decrease in self-reported task performance and to an increase in self-reported effort expenditure after vacation.

\section{Resource-Providing Vacation Experiences}

There may be experiences during vacation that can help to build resources and decrease the experience of stress, such as positive work reflection, mastery experience, and relaxation. These experiences should result in higher well-being and job performance after vacation. In contrast to negative work reflection, positive work reflection denotes considering the positive aspects of one's job and realizing what one likes about it. Positive reflection could be one mechanism to regain lost resources and to facilitate further resource gains (Westman, 1999). For example, noticing one's achieved goals and fulfilled tasks may provide resources such as a sense of competence and self-efficacy, resulting in increased wellbeing (Bandura, 1997) and job performance (Stajkovic \& Luthans, 1998).

Relaxation, a possible strategy to prevent upcoming stress or to cope with acute or chronic stressors (e.g., Jin, 1992; Thayer, Newman, \& McClain, 1994), may play an important role in recovery processes during vacation. Relaxing activities, such as reading a nice book; taking a long, quiet walk; or getting involved in specific relaxation strategies, such as meditation, allow the build-up of resources, which becomes apparent in lower levels of burnout and health complaints. In addition, resources gained during vacation can be invested into work, which results in higher levels of reported task performance and lower levels of effort that one needs to expend to reach the expected level of task performance.

Mastery experience refers to activities that act as an individual challenge or that offer the possibility to learn new skills, such as taking language classes, learning a new sport, or undertaking a mountain expedition. Pursuing mastery-related activities during vacation may provide resources by enhancing positive mood (Parkinson \& Totterdell, 1999). Moreover, successfully facing a challenge and learning something new may enhance self-efficacy and constitute a resource that may become apparent in subsequent well-being (Bandura, 1997) and job performance (Stajkovic \& Luthans, 1998).

Thus, we hypothesized that positive work reflection, relaxation, and mastery experiences during vacation would lead to a reduction in health complaints, burnout, and self-reported effort expenditure and to an increase in self-reported task performance after vacation.

Hypothesis 7: Resource-providing vacation experiences (positive work reflection, relaxation, and mastery experience) will lead to a reduction in health complaints and burnout after vacation.

Hypothesis 8: Resource-providing vacation experiences (positive work reflection, relaxation, and mastery experience) will lead to an increase in self-reported task performance and to a decrease in self-reported effort expenditure after vacation.

\section{The Role of Workload After Vacation}

During vacation, work often piles up, so that, upon return, the employee needs to work off all these chores before being able to pursue his or her everyday work tasks. This elevated level of work demands may quickly use up gained resources and increase the need for recovery, becoming apparent in lower levels of wellbeing. In addition, the individual has fewer resources to invest into work, so task performance decreases and the effort needed to fulfill the daily work tasks increases. Thus, we assumed that workload immediately after vacation would have a negative impact on well-being and performance-related outcomes.

Hypothesis 9: Workload immediately after vacation will lead to an increase in health complaints and burnout.

Hypothesis 10: Workload immediately after vacation will lead to a reduction in self-reported task performance and an increase in self-reported effort expenditure.

\section{Method}

\section{Sample and Procedure}

Participants were German nonacademic university employees. After universities consented to involvement in the study, participants were recruited by e-mail. Survey packages were sent out to 414 employees who consented to participate and reported having at least one week of vacation within the following few months. Each survey package consisted of an information letter, four clearly distinguishable survey booklets, and a stamped, preaddressed return envelope. The first survey booklet had to be filled in 1 week before vacation (Time 1), the second during vacation (Time 2), the third within the first 2 days after vacation (Time 3), and the fourth 2 weeks after vacation (Time 4). After participants had filled in all four survey booklets, they sent them back to us in a single envelope.

Out of the 233 questionnaires returned (response rate $=56.28 \%$ ), 12 had to be left out of the analyses because of missing data. The final sample of 221 participants included 189 women $(85.50 \%)$ and 32 men $(14.50 \%)$ Participants mainly fulfilled clerical tasks (e.g., administration secretary, accounting clerk, legal advisor). The average age of participants was 45.91 years $(S D=8.92)$. Mean job experience was 20.79 years $(S D=11.10)$ About a third $(34.40 \%)$ of the participants held a university degree. Average contract working time per week was $29.04 \mathrm{hr}(S D=11.65)$. One hundred forty-eight participants $(66.96 \%)$ had at least one child. Means and standard deviations for each scale, variable intercorrelations, and alpha coefficients of all study variables are presented in Table 1.

\section{Measures}

\section{Well-Being}

Health complaints. Twelve items from the General Health Questionnaire (Goldberg, 1978; e.g., "Have you slept less because of worries?") were used to measure health complaints before (Time 1) and after vacation (Time 3 and Time 4). Responses were given on a 4-point rating scale ranging from 1 (not at all) to 4 (much more than normal). Cronbach's alphas were $.89, .86$, and .91 for Time 1 , Time 3 , and Time 4 , respectively

Burnout. Burnout before (Time 1) and after vacation (Time 3 and Time 4) was measured with the Oldenburg Burnout Inventory (Demerouti et al., 2001). The two subscales, Exhaustion (e.g., "During my work, I often feel emotionally drained") and Disengagement (e.g., "With time, one loses the internal relationship with one's work") were each quantified with eight items on 4-point rating scales that ranged from 1 (totally agree) to 4 (totally disagree). Cronbach's alphas for exhaustion and disengagement, respec- 
tively, were .74 and .84 at Time $1, .81$ and .86 at Time 3 , and .82 and .88 at Time 4.

To test the factor structure of our well-being scales, we conducted confirmatory factor analyses for exhaustion, disengagement, and health complaints at Time 1, Time 3, and Time 4 . We examined whether, for each measurement occasion, the three-factor model was superior to a one-factor model. We used a chi-square difference test to compare model fits. The three-factor model provided a fit superior to that of a one-factor model at Time $1, \Delta \chi^{2}(3, N=221)=1,259.87, p<.01$; Time $3, \Delta \chi^{2}(3, N=221)=$ $1,089.16, p<.01 ;$ and Time $4, \Delta \chi^{2}(3, N=221)=1387.76, p<.01$.

\section{Performance-Related Outcomes}

Self-reported task performance. We quantified task performance before (Time 1) and after vacation (Time 3 and Time 4) with five items from an in-role behavior scale from Williams and Anderson (1991; e.g., "I perform the tasks that are expected from me"). Response categories ranged from 1 (not true at all) to 5 (totally true). Cronbach's alphas were .79, .76, and .78 for Time 1 , Time 3 , and Time 4 , respectively.

Self-reported effort expenditure. We assessed the level of necessary effort expenditure before (Time 1) and after vacation (Time 3 and Time 4) with three items adapted from Earley, Wojnaroski, and Prest (1987). Items were "I need to expend much energy to accomplish my everyday assignments at work," "I need to spend much perceived effort to fulfill my regular work tasks," and "I realize that I spend much perceived effort while pursuing my work." Responses were given on 5-point rating scales ranging from 1 (not true at all) to 5 (totally true). Cronbach's alphas were $.92, .95$, and .95 for Time 1, Time 3, and Time 4, respectively. Confirmatory factor analyses including task performance and effort expenditure items for Time 1, Time 3, and Time 4 revealed that, for each measurement occasion, a two-factor model fit the data better than a one-factor model: Time $1, \Delta \chi^{2}(1$, $N=221)=412.59, p<.01$; Time $3, \Delta \chi^{2}(1, N=221)=382.14, p<.01$; Time $4, \Delta \chi^{2}(1,221)=286.95, p<.01$.

\section{Vacation Experiences}

All vacation experiences measures were administered during vacation (Time 2) and used 5-point rating scales ranging from 1 (not true at all) to 5 (totally true).

Resource-consuming vacation experiences. We assessed negative work reflection with three items asking how much the employee thought about his or her work in a negative manner (i.e., "During vacation, I realized what I did not like about my job," "During vacation, I considered the negative aspects of my job," and "During vacation, I noticed what is negative about my work"). Cronbach's alpha was .85 . We measured the amount of nonwork hassle by adapting nine items from a measure developed by Bolger, DeLongis, Kessler, and Schilling (1989). Items, for example, referred to conflicts with the participant's partner or other persons, financial problems, or problems with the car (e.g., "During vacation, I had conflicts with other persons"). Cronbach's alpha was .72.

Resource-providing vacation experiences. We measured positive work reflection during vacation with three items that asked how much the individual positively thought about aspects of his or her job during vacation (i.e., "During vacation, I realized what I like about my job," "During vacation, I thought about the positive points of my job," and "During vacation, I considered the positive aspects of my job"). Cronbach's alpha was .86. We used three items to measure relaxation experiences (i.e., "During vacation, I did things that were relaxing," "During vacation, I let my soul dangle," and "During vacation, I took time to laze"). Cronbach's alpha was .78. We gauged mastery experience with three items asking the degree to which the individual pursued activities during vacation that included a challenge or learning something new (i.e., "During vacation, I pursued activities to expand my horizon," "During vacation, I did things that challenged me," and "During vacation, I learned new things"). Cron- bach's alpha was .66. Confirmatory factor analyses including all vacation experiences revealed that a five-factor model, as we proposed it, fit the data better than a one-factor model, $\Delta \chi^{2}(10, N=221)=1,192.57, p<.01$.

\section{Workload After Vacation}

To assess employee's' workload after vacation (Time 3), we adapted seven items from Karasek's (1979) scale of job demands and added two items asking for possible extra work as a result of vacation (e.g., "At my work I need to do more tasks than at other times," "Due to vacation a lot of work piled up on my desk"). Responses were given on 5-point rating scales ranging from 1 (not true at all) to 5 (totally true). Cronbach's alpha was .95 .

\section{Control Variables}

Negative affectivity. Previous research indicated associations between self-reports of negative affectivity and job strain and suggested the measurement of the first variable in the study on job stress (Brief, Burke, George, Robinson, \& Webster, 1988; Burke, Brief, \& George, 1993). Therefore, we measured negative affectivity before vacation (Time 1) with 10 items from the Positive and Negative Affect Schedule (Watson, Clark, $\&$ Tellegen, 1988). Participants were asked on a 5-point rating scale how they felt "in general" referring to 10 adjectives indicating negative affect. Cronbach's alpha was .88.

Vacation length. Because previous research discussed the role of vacation length in the vacation effect (Etzion, 2003), we included the number of days off from work as a control variable and measured it during vacation (Time 2).

Demographic variables. We controlled for gender, age, and whether participants had children because previous research indicated the relevance of these variables in recovery from work demands (e.g., Sonnentag, 2001, 2003).

\section{Results}

\section{General Effects of Vacation on Well-Being and Performance-Related Outcomes}

We conducted repeated measures analyses of variance including the three measurement occasions (Time 1, Time 3, and Time 4) to examine changes in the outcome variables from Time 1 to Time 3 (vacation effect) and from Time 3 to Time 4 (fade-out effect). The results, shown in Table 2, indicate that health complaints changed across the three occasions, significantly declining from 1 week before vacation (Time 1) to immediately after the vacation (Time 3), $F(1,221)=114.92, p<.01$, and increasing again from immediately after vacation to 2 weeks after vacation (Time 4$), F(1$, $221)=28.26, p<.01$. Analyses of variance for exhaustion showed an overall effect of time, including a decline in exhaustion from Time 1 to Time 3, indicating a vacation effect, $F(1,221)=$ 22.48, $p<.01$, but no significant difference between Time 3 and Time $4, F(1,221)=0.59$. Disengagement did not change from Time 1 to Time $3, F(1,220)=2.99$, or from Time 3 to Time 4 , $F(1,220)=0.04$. Overall, the results reveal an ameliorative effect of vacation on health complaints and exhaustion but not on disengagement, partially supporting Hypothesis 1. In addition, we found significant differences between Time 3 and Time 4 for health complaints, which indicates a fade-out effect, as proposed in Hypothesis 3.

Analyses of variance for self-reported task performance revealed that task performance did not change from Time 1 to Time 
Table 1

Means, Standard Deviations, and Zero-Order Correlations Between Study Variables

\begin{tabular}{|c|c|c|c|c|c|c|c|c|c|c|c|c|c|}
\hline Variable & $M$ & $S D$ & 1 & 2 & 3 & 4 & 5 & 6 & 7 & 8 & 9 & 10 & 11 \\
\hline 1. Age & 45.97 & 8.93 & - & & & & & & & & & & \\
\hline 2. Gender & 0.14 & 0.35 & $.16 *$ & - & & & & & & & & & \\
\hline 3. Having children & 0.67 & 0.47 & $.32 * *$ & -.08 & - & & & & & & & & \\
\hline 4. Negative affectivity & 1.71 & 0.65 & -.12 & -.06 & -.06 & .88 & & & & & & & \\
\hline $\begin{array}{l}\text { 5. Vacation length } \\
\text { 6. Nonwork hassles }\end{array}$ & 18.27 & 6.53 & -.09 & -.01 & $.14^{*}$ & .06 & - & & & & & & \\
\hline $\begin{array}{l}\text { T2 } \\
\text { 7. Positive work }\end{array}$ & 1.64 & 0.55 & -.08 & -.05 & $.16^{*}$ & $.31^{* *}$ & $.15^{*}$ & .72 & & & & & \\
\hline $\begin{array}{l}\text { reflection T2 } \\
\text { 8. Negative work }\end{array}$ & 2.29 & 0.97 & .02 & .06 & .11 & .07 & $.19 * *$ & .08 & .86 & & & & \\
\hline reflection $\mathrm{T} 2$ & 1.66 & 0.81 & $-.15^{*}$ & .03 & $-.17 *$ & $.35^{* *}$ & .07 & $.24 * *$ & $.32 * *$ & .85 & & & \\
\hline 9. Relaxation $\mathrm{T} 2$ & 4.01 & 0.74 & -.02 & -.05 & -.06 & $-.20 * *$ & -.02 & $-.39 * *$ & $.14 *$ & -.05 & .78 & & \\
\hline 10. Mastery T2 & 3.08 & 0.81 & $.17 *$ & .20 & .11 & $.16^{*}$ & .08 & .10 & .05 & .12 & $.14 *$ & .66 & \\
\hline $\begin{array}{l}\text { 11. Workload T3 } \\
\text { 12. Health complaints }\end{array}$ & 2.97 & 1.10 & .00 & -.06 & .02 & $-.24 * *$ & .01 & -.11 & $-.14^{*}$ & $.15^{*}$ & -.03 & -.10 & .95 \\
\hline $\begin{array}{l}\text { T1 } \\
\text { 13. Health complaints }\end{array}$ & 1.94 & 0.47 & -.09 & $-.16^{*}$ & .05 & $.60^{* *}$ & .07 & $.23^{* *}$ & -.07 & $.14^{*}$ & -.09 & $.15^{*}$ & $.17^{*}$ \\
\hline $\begin{array}{l}\text { T3 } \\
\text { 14. Health complaints }\end{array}$ & 1.59 & 0.35 & -.12 & .04 & $-.14^{*}$ & $.42 * *$ & -.03 & $.21 * *$ & .00 & $.39 * *$ & $-.20 * *$ & -.13 & .13 \\
\hline $\mathrm{T} 4$ & 1.71 & 0.42 & -.07 & .00 & -.12 & $.46^{* *}$ & .07 & $.30 * *$ & .10 & $.35^{* *}$ & $-.18^{* *}$ & -.06 & $.21 * *$ \\
\hline 15. Exhaustion T1 & 2.18 & 0.55 & .05 & -.02 & $-.15^{*}$ & $.41 * *$ & -.07 & $.21 * *$ & -.08 & $.36 * *$ & $-.13 *$ & -.04 & $.28 *$ \\
\hline 16. Exhaustion T3 & 2.05 & 0.55 & .01 & -.07 & -.10 & $.40^{* *}$ & -.07 & $.31 * *$ & -.04 & $.44 * *$ & $-.18^{*}$ & -.09 & $.36 *$ \\
\hline 17. Exhaustion T4 & 2.03 & 0.56 & .00 & -.03 & $-.18 * *$ & $.38 * *$ & -.02 & $.25^{* *}$ & .04 & $.44 * *$ & $-.18 * *$ & -.01 & $.36^{*}$ \\
\hline 18. Disengagement T1 & 2.10 & 0.53 & $-.17 * *$ & -.05 & $-.22 * *$ & $.26^{* *}$ & .05 & $.17 * *$ & -.05 & $.31 *$ & -.13 & .00 & -.01 \\
\hline 19. Disengagement $\mathrm{T} 3$ & 2.06 & 0.53 & $-.20 * *$ & -.08 & $-.19 * *$ & $.31 *$ & .00 & $.23 *$ & -.09 & $.38 * *$ & -.17 & -.05 & -.03 \\
\hline $\begin{array}{l}\text { 20. Disengagement } \mathrm{T} 4 \\
\text { 21. Task performance }\end{array}$ & 2.06 & 0.54 & $-.19 * *$ & -.05 & $-.23 * *$ & $.33 * *$ & .00 & $.19^{*}$ & -.07 & $.40 * *$ & -.09 & -.04 & .02 \\
\hline $\begin{array}{l}\text { T1 } \\
\text { 22. Task performance }\end{array}$ & 4.51 & 0.49 & -.07 & -.09 & .00 & $-.23 * *$ & $.14 *$ & $-.14 *$ & -.02 & $-.19 * *$ & .13 & -.04 & -.08 \\
\hline $\begin{array}{l}\text { T3 } \\
\text { 23. Task performance }\end{array}$ & 4.49 & 0.54 & -.05 & -.11 & .10 & $-.26 * *$ & .06 & -.11 & -.04 & $-.28 * *$ & .04 & .04 & $-.29 * *$ \\
\hline $\begin{array}{l}\text { T4 } \\
\text { 24. Effort expenditure }\end{array}$ & 4.45 & 0.55 & -.06 & $-.17 * *$ & .11 & $-.18 * *$ & .10 & $-.16^{*}$ & -.08 & $-.18 * *$ & .12 & -.05 & $-.14 *$ \\
\hline $\begin{array}{l}\mathrm{T} 1 \\
\text { 25. Effort expenditure }\end{array}$ & 2.90 & 1.14 & .13 & .03 & .10 & $.28 * *$ & .04 & $.17 *$ & .06 & .12 & -.07 & .06 & $.44 * *$ \\
\hline $\begin{array}{l}\text { T3 } \\
\text { 26. Effort expenditure }\end{array}$ & 2.26 & 1.15 & .06 & .10 & .04 & $.24 * *$ & .00 & $.14^{*}$ & -.03 & $.17^{*}$ & -.07 & .02 & $.59 * *$ \\
\hline $\mathrm{T} 4$ & 2.31 & 1.15 & -.04 & .09 & -.11 & $.32 * *$ & .01 & $.30 * *$ & .06 & $.37 * *$ & $.24 * *$ & .03 & $.37 * *$ \\
\hline
\end{tabular}

Note. Values on the diagonal represent Cronbach's alphas for the measures. $\mathrm{T} 1=$ before vacation; $\mathrm{T} 2=$ during vacation; $\mathrm{T} 3=$ immediately after vacation; T4 $=2$ weeks after vacation. Gender: $0=$ female, $1=$ male. Having children: $0=$ no, $1=$ yes

$* p<.05 . \quad * * p<.01$.

$3, F(1,221)=0.25$, or from Time 3 to Time $4, F(1,221)=1.85$. In contrast, self-reported effort expenditure showed a significant decrease from Time 1 to Time 3, $F(1,220)=60.15, p<.01$, and stayed at this level until Time $4, F(1,220)=0.35$, ns. Thus, findings regarding performance-related outcomes partially supported the assumption of a vacation effect (Hypothesis 2) but not the assumption of a fade-out effect (Hypothesis 4).

\section{Effects of Specific Vacation Experiences and Workload After Vacation}

We used hierarchical regression analyses to test Hypotheses 5 to 10. We entered demographic variables (gender, age, and having children), negative affectivity, and vacation length into the equation in Step 1 to predict well-being and performance-related outcomes at Time 3 and Time 4. To control for the level of the outcome variables before vacation, we entered well-being and performance-related outcomes before vacation (Time 1) into the equation in Step 2. In Step 3, we included the resource-consuming and resource-providing vacation experiences to test whether they explained variance in the outcome variables beyond the control variables and the outcome variable before vacation. In Step 4, we added workload after vacation, which we assessed at Time 3.

\section{Well-Being}

Table 3 shows that control variables entered into the regression in Step 1 were significantly related to health complaints at Time 3 or Time 4, whereas health complaints before vacation were not a significant predictor. Overall, vacation experiences were significantly associated with health complaints immediately after vacation and 2 weeks later. In more detail, negative work reflection during vacation significantly predicted health complaints after vacation. Positive work reflection, mastery experience, relaxation, and nonwork hassles were not significantly related to health complaints after vacation. Finally, workload immediately after vacation (Time 3 ) did not predict health complaints at Time 3 and Time 4 . 


\begin{tabular}{lllllllllllllll}
\hline 12 & 13 & 14 & 15 & 16 & 17 & 18 & 19 & 20 & 21 & 22 & 23 & 24 & 25 & 26 \\
\hline
\end{tabular}

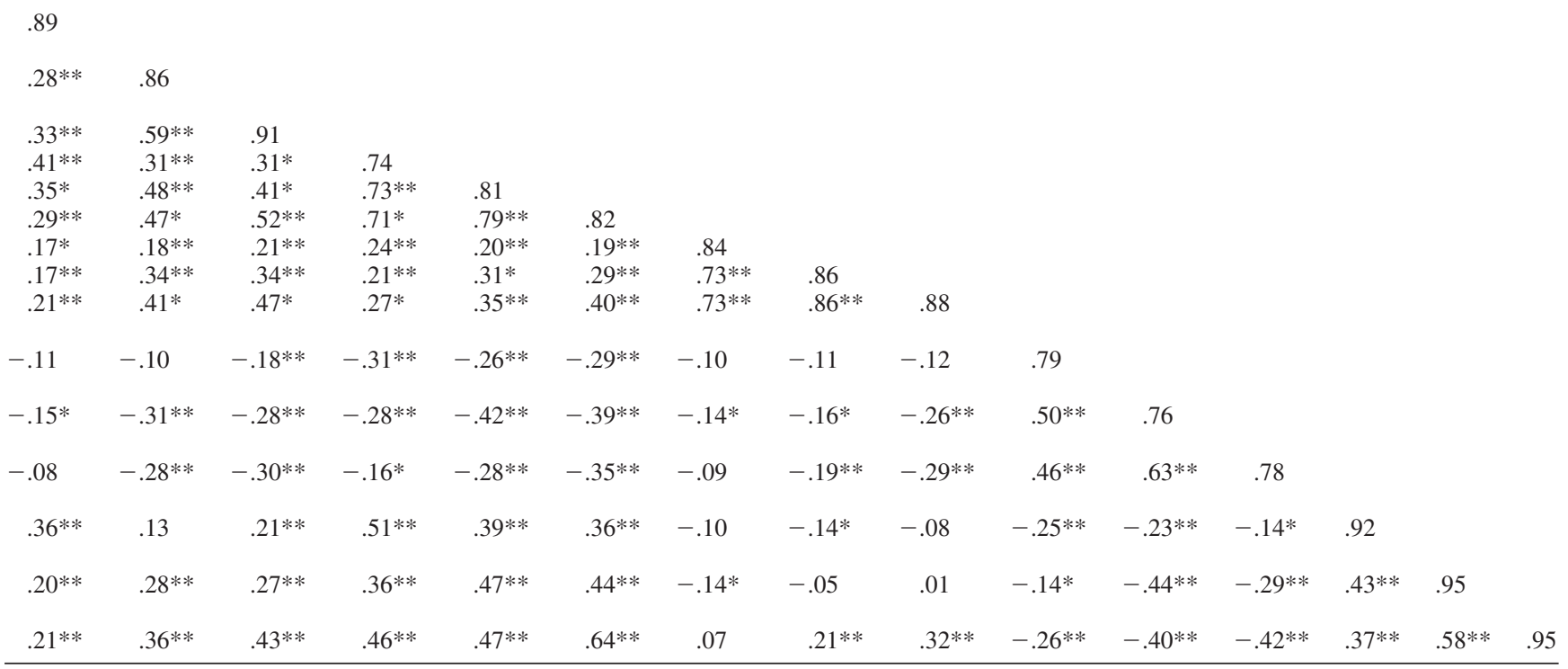

Table 4 indicates that, after we controlled for demographic variables, vacation length, negative affectivity, and exhaustion at Time 1, vacation experiences were significantly related to exhaustion at Time 3 and Time 4. In particular, employees who were high in negative work reflection felt more exhausted on their return to work and 2 weeks later. In addition, employees who experienced high levels of nonwork hassles during vacation reported higher levels of exhaustion on their return to work. Positive work reflection and relaxation were not significantly associated with exhaustion at Time 3 or Time 4. However, higher levels of mastery

Table 2

Analysis of Variance for Well-Being and Performance-Related Outcomes Comparing Measures for Time 1, Time 3, and Time 4

\begin{tabular}{lccccccc}
\hline \multicolumn{1}{c}{ Variable } & Time $1 M$ & Time $3 M$ & Time $4 M$ & $d f$ & $N$ & $F$ & $\eta^{2}$ \\
\hline Health complaints & 1.94 & 1.59 & 1.71 & 2 & 222 & $57.44^{* * *}$ & .34 \\
Exhaustion & 2.18 & 2.05 & 2.03 & 2 & 221 & $14.78^{* *}$ & .12 \\
Disengagement & 2.10 & 2.06 & 2.06 & 2 & 220 & 1.78 & .02 \\
Task performance & 4.51 & 4.49 & 4.45 & 2 & 222 & 1.60 & .01 \\
Effort expenditure & 2.90 & 2.26 & 2.31 & 2 & 221 & $33.07^{* *}$ & .23 \\
\hline
\end{tabular}

$* * p<.01$. 
Table 3

Hierarchical Regression of Health Complaints on Vacation Experiences and Workload

\begin{tabular}{|c|c|c|c|c|}
\hline \multirow[b]{2}{*}{ Variable } & \multicolumn{2}{|c|}{ Time 3} & \multicolumn{2}{|c|}{ Time 4} \\
\hline & $\beta$ & $\Delta R^{2}$ & $\beta$ & $\Delta R^{2}$ \\
\hline Step 1: Control variables & & $.20 * *$ & & $.23 * *$ \\
\hline Age & -.02 & & .03 & \\
\hline Gender & .05 & & .01 & \\
\hline Having children & -.07 & & -.14 & \\
\hline Negative affectivity & $.25 * *$ & & $.27 * *$ & \\
\hline Vacation length & -.04 & & .03 & \\
\hline Step 2: Health complaints (Time 1) & .05 & .00 & .09 & .01 \\
\hline Step 3: Vacation experiences (Time 2) & & $.08 * *$ & & $.06 * *$ \\
\hline Positive work reflection & -.06 & & .04 & \\
\hline Negative work reflection & $.27 * *$ & & $.16^{*}$ & \\
\hline Mastery & -.09 & & -.04 & \\
\hline Relaxation & -.08 & & -.05 & \\
\hline Nonwork hassles (Time 2) & .04 & & .13 & \\
\hline Step 4: Workload (Time 3) & .06 & .00 & .12 & .01 \\
\hline Total $R^{2}$ & & $.28 * *$ & & $.31 * *$ \\
\hline
\end{tabular}

Note. Gender: $0=$ female, $1=$ male. Having children: $0=$ no, $1=$ yes. Beta weights refer to the full model.

$* p<.05 . \quad * * p<.01$.

experience during vacation were associated with lower levels of exhaustion on the employee's return to work (Time 3). Finally, high workload after vacation (Time 3) was related to high levels of concurrent and subsequent exhaustion.

Analyses regarding disengagement indicated that control variables and disengagement at Time 1 significantly related to disengagement immediately after vacation (Time 3 ) and 2 weeks later (Time 4). Specific vacation experiences significantly accounted for variance in disengagement at Time 3 and Time 4 . That is, high levels of negative work reflection were related to high levels of disengagement immediately after vacation and 2 weeks later. In contrast, nonwork hassles were not significantly related to disengagement after vacation. With regard to resource-providing experiences, employees who were high in positive work reflection during vacation showed lower levels of disengagement when they returned to work. Mastery experience and relaxation as well as workload immediately after vacation were not significantly related to disengagement after vacation.

Overall, vacation experiences contributed to all indicators of well-being immediately after vacation and 2 weeks later. This contribution resulted over and above the contribution of negative affectivity and well-being before vacation, which lends some support to Hypothesis 5 and Hypothesis 7. In addition, we found significant effects of workload on exhaustion, so Hypothesis 9 was partially supported.

\section{Performance-Related Outcomes}

As Table 5 shows, control variables and self-reported task performance at Time 1 significantly accounted for variance in self-reported task performance after vacation. Vacation experiences were not significantly associated with task performance immediately after vacation or 2 weeks later. In contrast, workload after vacation was significantly negatively associated with selfreported task performance at Time 3 .

Self-reported effort expenditure after vacation was significantly predicted by control variables and effort expenditure before vacation. Vacation experiences did not significantly contribute to effort expenditure at Time 3 but did have a significant effect at Time 4 . That is, participants who were high in negative work reflection reported expending more effort 2 weeks after vacation. In addition, employees with higher levels of nonwork hassles during their vacation reported higher levels of expended effort 2 weeks after their return to work. Furthermore, relaxation during vacation was negatively related to perceived effort 2 weeks after vacation. Positive work reflection and mastery experience during vacation

Table 4

Hierarchical Regression of Burnout on Vacation Experiences and Workload

\begin{tabular}{|c|c|c|c|c|c|c|c|c|}
\hline \multirow[b]{2}{*}{ Variable } & \multicolumn{2}{|c|}{$\begin{array}{l}\text { Exhaustion } \\
\text { (Time 3) }\end{array}$} & \multicolumn{2}{|c|}{$\begin{array}{l}\text { Exhaustion } \\
\text { (Time 4) }\end{array}$} & \multicolumn{2}{|c|}{$\begin{array}{l}\text { Disengagement } \\
\text { (Time 3) }\end{array}$} & \multicolumn{2}{|c|}{$\begin{array}{l}\text { Disengagement } \\
\quad \text { (Time 4) }\end{array}$} \\
\hline & $\beta$ & $\Delta R^{2}$ & $\beta$ & $\Delta R^{2}$ & $\beta$ & $\Delta R^{2}$ & $\beta$ & $\Delta R^{2}$ \\
\hline Step 1: Control variables & & $.19 * *$ & & $.19 * *$ & & $.15 * *$ & & $.17 * *$ \\
\hline Age & .01 & & .01 & & -.04 & & -.03 & \\
\hline Gender & -.07 & & -.05 & & -.03 & & -.01 & \\
\hline Having children & -.01 & & $-.10 *$ & & .00 & & -.04 & \\
\hline Negative affectivity & .03 & & .03 & & .06 & & .09 & \\
\hline Vacation length & -.05 & & .00 & & -.03 & & -.03 & \\
\hline Step 2: Outcome variable (Time 1) & $.56^{* * *}$ & $.36 * *$ & $.54 * *$ & $.33 * *$ & $.63 * *$ & $.41 * *$ & $.63 * *$ & $.39 * *$ \\
\hline Step 3: Vacation experiences (Time 2) & & $.05 * *$ & & $.04 * *$ & & $.04 * *$ & & $.03 * *$ \\
\hline Positive work reflection & -.03 & & .04 & & $-.12 *$ & & -.10 & \\
\hline Negative work reflection & $.20 * *$ & & $.16^{* *}$ & & $.20 * *$ & & $.19 * *$ & \\
\hline Mastery & $-.10 *$ & & -.03 & & -.03 & & -.04 & \\
\hline Relaxation & -.02 & & -.07 & & -.03 & & -.04 & \\
\hline Nonwork hassles (Time 2) & $.11 *$ & & .05 & & .06 & & .03 & \\
\hline Step 4: Workload (Time 3) & $.18^{* *}$ & $.03 * *$ & $.18^{* *}$ & $.03 * *$ & -.05 & .00 & .01 & .00 \\
\hline Total $R^{2}$ & & $.63 * *$ & & $.59 * *$ & & $.59 * *$ & & $.59 * *$ \\
\hline
\end{tabular}

Note. Gender: $0=$ female, $1=$ male. Having children: $0=$ no, $1=$ yes. Beta weights refer to the full model. $* p<.05$. ** $p<.01$. 
Table 5

Hierarchical Regression of Performance-Related Outcomes on Vacation Experiences and Workload

\begin{tabular}{|c|c|c|c|c|c|c|c|c|}
\hline \multirow[b]{2}{*}{ Variable } & \multicolumn{2}{|c|}{$\begin{array}{l}\text { Task performance } \\
\text { (Time 3) }\end{array}$} & \multicolumn{2}{|c|}{$\begin{array}{l}\text { Task performance } \\
\text { (Time 4) }\end{array}$} & \multicolumn{2}{|c|}{$\begin{array}{l}\text { Effort expenditure } \\
\text { (Time 3) }\end{array}$} & \multicolumn{2}{|c|}{$\begin{array}{l}\text { Effort expenditure } \\
\text { (Time 4) }\end{array}$} \\
\hline & $\beta$ & $\Delta R^{2}$ & $\beta$ & $\Delta R^{2}$ & $\beta$ & $\Delta R^{2}$ & $\beta$ & $\Delta R^{2}$ \\
\hline Step 1: Control variables & & $.12^{* *}$ & & $.10^{* *}$ & & $.08 * *$ & & $.11^{* *}$ \\
\hline Age & -.07 & & -.07 & & -.03 & & -.03 & \\
\hline Gender & -.06 & & $-.14 *$ & & .09 & & .06 & \\
\hline Having children & .11 & & $.15^{*}$ & & .02 & & -.12 & \\
\hline Negative affectivity & -.08 & & -.03 & & .09 & & .06 & \\
\hline Vacation length & .07 & & .07 & & -.04 & & -.04 & \\
\hline Step 2: Outcome variable (Time 1) & $.43 * *$ & $.18^{* *}$ & $.37 * *$ & $.14^{* *}$ & $.18^{* *}$ & $.14 * *$ & $.20^{* *}$ & $.09 * *$ \\
\hline Step 3: Vacation experiences (Time 2) & & .03 & & .02 & & .02 & & $.11^{* *}$ \\
\hline Positive work reflection & .01 & & -.08 & & -.07 & & -.02 & \\
\hline Negative work reflection & -.11 & & -.01 & & .04 & & $.21 * *$ & \\
\hline Mastery & .08 & & -.02 & & -.03 & & .01 & \\
\hline Relaxation & -.08 & & .04 & & .01 & & $-.13^{*}$ & \\
\hline Nonwork hassles (Time 2) & -.05 & & -.12 & & .04 & & $.15^{*}$ & \\
\hline Step 4: Workload (Time 3) & $-.26 * *$ & $.06 * *$ & -.12 & .01 & $.51 * *$ & $.19^{* *}$ & $.25 * *$ & $.05 * *$ \\
\hline Total $R^{2}$ & & $.39 * *$ & & $.27^{* *}$ & & $.43 * *$ & & $.36^{* *}$ \\
\hline
\end{tabular}

Note. Gender: $0=$ female, $1=$ male. Having children: $0=$ no, $1=$ yes. Beta weights refer to the full model.

$* p<.05 . \quad * * p<.01$.

did not contribute to effort expenditure after vacation. However, employees who faced high levels of workload immediately after vacation reported that they needed more effort to fulfill their daily work tasks immediately after vacation and 2 weeks later. Overall, vacation experiences were significantly associated with selfreported effort expenditure 2 weeks after vacation but were not related to self-reported task performance, which lends some support to Hypothesis 6 and Hypothesis 8. In addition, workload immediately after vacation significantly predicted effort expenditure, partially supporting Hypothesis 10.

\section{Discussion}

This study had two main purposes: First, we examined general effects of vacation on well-being and performance-related outcomes immediately after vacation and fade-out effects 2 weeks after vacation. Second, we wanted to shed light on the importance of specific experiences during vacation as well as the amount of workload immediately after vacation with respect to well-being and performance-related outcomes after vacation. In particular, we examined the degree to which vacation experiences that are indicators of resource loss or resource gain have an impact on wellbeing and performance-related outcomes after vacation.

\section{General Effects of Vacation on Well-Being and Performance-Related Outcomes}

In accordance with previous vacation studies (Eden, 1990; Lounsbury \& Hoopes, 1986; Westman \& Eden, 1997), we found that health complaints and exhaustion significantly decreased during vacation. In addition, after vacation, less effort expenditure was necessary to fulfill the daily work chores. However, in contrast to Westman and Aharon-Madar's (1998) findings, our results did not reveal a change in self-reported task performance from before to after vacation. One reason for this result might be that the levels of reported task performance already were very high before vacation, so that an additional increase in task performance was less probable. In addition, it might be that our measure assessed rather stable aspects of task performance, so that changes due to vacation could not be found.

As in previous research (Eden, 2001), we found fade-out effects for health complaints 2 weeks after vacation. The reason we did not find fade-out of burnout and performance-related outcomes could lie in the relatively short time frame we used; we might have found stronger fade-out effects 3 or 4 weeks after vacation. However, our findings add to the assumption that fade-out describes a gradual change in well-being and performance-related outcomes after vacation, which could be due to the exhaustion of resources when the employee is back at work. Overall, our results suggest that during vacation recovery from work demands occurs and individual resources are replenished, which has consequences for well-being and-to a lesser extent-for performance-related outcomes.

\section{Effects of Specific Vacation Experiences and Workload After Vacation}

Regarding the role of specific vacation experiences, we assumed that gaining new resources would support recovery and reduce the experiences of stress, whereas additional loss of resources would impair individual functioning (Hobfoll, 1998). Overall, we found indications for both effects, which reveals the importance of resource gain and loss in the recovery process during vacation.

\section{Resource-Consuming Vacation Experiences}

Negative work reflection during vacation predicted all wellbeing indicators immediately after vacation and some indicators 2 weeks after vacation. Although the effect for self-reported task performance was not significant, it pointed in the same direction. It seems that negative thinking about work during vacation impairs recovery from work and impedes replenishment of resources. 
Because a vacation may not be a positive experience per se (Eden, 2001), we explicitly investigated the effect of nonwork hassles on well-being and performance-related outcomes, finding that nonwork hassles during vacation seemed to increase exhaustion and self-reported effort expenditure after vacation. Altogether, the strong effects of negative work reflection and-to a lesser degree-the effects of nonwork hassles on well-being and performance-related outcomes after vacation support the assumptions that the absence of stressors leads to recovery (Hobfoll, 1998; Meijman \& Mulder, 1998) and that resource-consuming experiences during vacation hinder the recovery process. In addition, the detrimental effects of workload immediately after vacation on performance-related outcomes and-to a lesser extent-wellbeing indicate that the pile of work that the employee expects on his or her return consumes a lot of the resources gained during vacation.

\section{Resource-Providing Vacation Experiences}

Our results regarding the effects of positive work reflection, mastery, and relaxation indicate that positive experiences during vacation seemed to rebuild resources, as reflected in well-being and performance-related outcomes when the employee returned to work. Results regarding the effect of positive work reflection on disengagement are in line with a recent study that showed a negative relation between positive work reflection during the weekend and disengagement after the weekend (Fritz \& Sonnentag, 2005). However, the effects of resource-providing vacation experiences were less strong than the effects of resourceconsuming experiences, which suggests that avoiding further resource depletion during vacation may be more important than explicitly pursuing activities that provide resources. This interpretation is in line with Hobfoll's (1998) assumption that resource loss is more salient than resource gain. Further research is necessary to make sure that our results are not due to the specific measures we used or the specific experiences we examined.

\section{Limitations and Strengths}

As with any study, this work has a number of limitations and strengths. First, the use of self-reports might have led to the inflation of our results through common method variance (Podsakoff, MacKenzie, Lee, \& Podsakoff, 2003). However, the longitudinal design of this study, the control for negative affectivity, and the differential pattern of relations among our measures lend support to the assumption that common method variance is not a major limitation of this study. Second, the measures we used to assess specific vacation experiences were newly developed, so more support for their validity is necessary. However, confirmatory factor analyses suggested that the experiences describe different constructs.

There are strengths in this study that bolster the importance of our findings. First, we applied a longitudinal design that included four measurement occasions, thereby allowing for a much stronger inference of causality than would the use of cross-sectional data. Second, because we measured well-being and performance-related outcomes before and after vacation, we could control for each variable at Time 1 when predicting the same variable at Time 3 or Time 4. After adding these and other control variables into the regression equation, we found that vacation experiences and workload still explained variance in the dependent variables. Third, by measuring well-being and performance-related outcomes immediately after vacation and 2 weeks later, we could differentiate between immediate and delayed effects and examine vacation fade-out.

\section{Implications for Research and Practice}

Our results point to the importance of examining variables that foster individual recovery from work demands. However, researchers clearly need to examine the generalizability of our findings to other employee groups. Maybe future research will show that different occupational groups need different activities during vacation to recover from work demands. Furthermore, our results referring to self-reported task performance still leave some open questions worth investigating. Further research should try to capture changes in performance-related outcomes by using measures that are more sensitive to performance change or by using supervisor reports or objective performance data.

Our findings have practical implications for vacation planning and management. Because of the resource-consuming character of nonwork hassles, individuals should explicitly look for recovery possibilities when facing high levels of nonwork hassles. Accordingly, individuals should avoid negative work reflection during vacation, as it seems to be highly detrimental for recovery. Furthermore, employees should try to avoid having a particularly high workload on their return to work, because it may consume additional resources, thereby impairing well-being and performancerelated outcomes. By planning ahead and distributing work tasks in a different way than usual while the employee is on vacation, management can avoid saddling the employee with an overly high workload after his or her vacation. Supervisors and organizations should clearly support their employees to ensure high levels of well-being and job performance and to decelerate fade-out effects.

Overall, by investigating resource-consuming and resourceproviding experiences during vacation and their effects on wellbeing and performance-related outcomes, our study contributes to previous research on vacation effects and recovery processes. We believe that this study is an important step in identifying off-thejob experiences that foster recovery from work demands and that have an impact on subsequent well-being and job performance.

\section{References}

Bandura, A. (1997). Self-efficacy: The exercise of control. New York: Freeman.

Bolger, N., DeLongis, A., Kessler, R. C., \& Schilling, E. A. (1989). Effects of daily stress on negative mood. Journal of Personality and Social Psychology, 57, 808-818.

Brief, A. P., Burke, M. J., George, J. M., Robinson, B. S., \& Webster, J. (1988). Should negative affectivity remain an unmeasured variable in the study of job stress? Journal of Applied Psychology, 73, 193-198.

Burke, M. J., Brief, A. P., \& George, J. M. (1993). The role of negative affectivity in understanding relations between self-reports of stressors and strains: A comment on the applied psychology literature. Journal of Applied Psychology, 78, 402-412.

Demerouti, E., Bakker, A. B., Nachreiner, F., \& Schaufeli, W. B. (2001) The job demands-resources model of burnout. Journal of Applied Psychology, 86, 499-512. 
Earley, P. C., Wojnaroski, P., \& Prest, W. (1987). Task planning and energy expended: Exploration of how goals influence performance. Journal of Applied Psychology, 72, 107-114.

Eden, D. (1990). Acute and chronic job stress, strain, and vacation relief. Organizational Behavior and Human Decision Processes, 45, 175-193.

Eden, D. (2001). Vacations and other respites: Studying stress on and off the job. In C. L. Cooper \& I. T. Robertson (Eds.), International review of industrial and organizational psychology (Vol. 16, pp. 121-146). New York: Wiley.

Etzion, D. (1984). Moderating effect of social support on the stressburnout relationship. Journal of Applied Psychology, 69, 615-622.

Etzion, D. (2003). Annual vacation: Duration and relief from job stress and burnout. Anxiety, Stress and Coping: An International Journal, 16, 213-226.

Etzion, D., Eden, D., \& Lapidot, Y. (1998). Relief from job stressors and burnout: Reserve service as a respite. Journal of Applied Psychology, 83, 377-585.

Fritz, C., \& Sonnentag, S. (2005). Recovery, health, and job performance: Effects of weekend experiences. Journal of Occupational Health Psychology, 10, 187-199.

Glaser, R., Kiecolt-Glaser, J. K., Speicher, C. E., \& Holliday, J. E. (1985). Stress, loneliness, and changes in herpes virus latency. Journal of Behavioral Medicine, 8, 249-260.

Goldberg, D. (1978). Manual of the General Health Questionnaire. London: Oxford University Press.

Hobfoll, S. E. (1998). Stress, culture, and community: The psychology and philosophy of stress. New York: Plenum Press.

Hockey, G. R. (1997). Compensatory control in the regulation of human performance under stress and high workload: A cognitive-energetical framework. Biological Psychology, 45, 73-93.

Jin, P. (1992). Efficacy of Tai Chi, brisk walking, meditation, and reading in reducing mental and emotional stress. Journal of Psychosomatic Research, 36, 361-370.

Karasek, R. A. (1979). Job demands, job decision latitude, and mental strain: Implications for job design. Administrative Science Quarterly, 24, 285-308.

Lounsbury, J. W., \& Hoopes, L. L. (1986). A vacation from work: Changes in work and nonwork outcomes. Journal of Applied Psychology, 71, 392-401.

Meijman, T. F., \& Mulder, G. (1998). Psychological aspects of workload. In P. J. D. Drenth, H. Thierry, \& C. J. de Wolff (Eds.), Handbook of work and organizational psychology (Vol. 2, pp. 5-33). Hove, England: Psychology Press.
Parkinson, B., \& Totterdell, P. (1999). Classifying affect-regulation strategies. Cognition and Emotion, 13, 277-303.

Podsakoff, P. M., MacKenzie, S. B., Lee, J.-Y., \& Podsakoff, N. P. (2003). Common method biases in behavioral research: A critical review of the literature and recommended remedies. Journal of Applied Psychology, $88,879-903$

Sonnentag, S. (2001). Work, recovery activities, and individual well-being: A diary study. Journal of Occupational Health Psychology, 6, 196-210.

Sonnentag, S. (2003). Recovery, work engagement, and proactive behavior. A new look at the interface between nonwork and work. Journal of Applied Psychology, 88, 518-528.

Sonnentag, S., \& Bayer, U. (2004). Switching off mentally: Predictors and consequences of psychological detachment from work during off-job time. Manuscript submitted for publication.

Stajkovic, A. D., \& Luthans, F. (1998). Self-efficacy and work-related performance: A meta-analysis. Psychological Bulletin, 124, 240-261.

Thayer, R. E., Newman, J. R., \& McClain, T. M. (1994). Self-regulation of mood: Strategies for changing a bad mood, raising energy, and reducing tension. Journal of Personality and Social Psychology, 67, 910-925.

Watson, D., Clark, L. A., \& Tellegen, A. (1988). Development and validation of brief measures of positive and negative affect: The PANAS scales. Journal of Personality and Social Psychology, 54, 1063-1070.

Watson, D., \& Pennebaker, J. W. (1989). Health complaints, stress, and distress: Exploring the central role of negative affectivity. Psychological Review, 96, 234-254.

Westman, M. (1999, August). Gain and loss spirals: Applying Hobfoll's COR theory to respite research. Paper presented at the meeting of the Academy of Management, Chicago, IL.

Westman, M., \& Aharon-Madar, M. (1998, May 27-29). The impact of vacation on stress, burnout, and performance. Paper presented at the 7th International Conference on Social Stress, Budapest, Hungary.

Westman, M., \& Eden, D. (1997). Effects of a respite from work on burnout: Vacation relief and fade out. Journal of Applied Psychology, $82,516-527$

Westman, M., \& Etzion, D. (2001). The impact of vacation and job stress on burnout and absenteeism. Psychology and Health, 16, 595-606.

Williams, L. J., \& Anderson, S. E. (1991). Job satisfaction and organizational commitment as predictors of organizational citizenship and in-role behaviors. Journal of Management, 17, 601-617.

Received June 30, 2004

Revision received March 22, 2005 Accepted March 31, 2005 